\title{
ON THE EXTENSION OF THE ERDÖS-MORDELL TYPE INEQUALITIES
}

\section{B. Malešević, M. Petrović, M. Obradović and B. Popkonstantinović}

Abstract. We discuss the extension of inequality $R_{A} \geqslant \frac{c}{a} r_{b}+\frac{b}{a} r_{c}$ to the plane of triangle $\triangle A B C$. Based on the obtained extension, in regard to all three vertices of the triangle, we get the extension of Erdös-Mordell inequality, and some inequalities of Erdös-Mordell type.

Mathematics subject classification (2010): 51M16, 51M04, 14H50.

Keywords and phrases: Erdös-Mordell inequality, inequality of Child, Erdös-Mordell curve.

\section{REFERENCES}

[1] C. Alsina, R. B. Nelsen, A Visual Proof of the Erdös-Mordell Inequality, Forum Geom. 7 (2007), 99-102.

[2] C. Alsina, R. B. Nelsen, When Less is More: Visualizing Basic Inequalities, Math. Association of America, Ch. 7 (pp. 93-99.), 2009.

[3] A. Avez, A Short Proof of a Theorem of Erdös and Mordell, Amer. Math. Monthly 100, 1 (1993), $60-62$.

[4] L. BAnKoff, An elementary proof of the Erdös-Mordell theorem, Amer. Math. Monthly 65 (1958), 521.

[5] M. Bombardelli, S. H. Wu, Reverse inequalities of Erdös-Mordell type, Math. Inequal. Appl. 12, 2 (2009), 403-411.

[6] O. Bottema, R. Ž. Djordjević, R. R. Janić, D. S. Mitrinović, P. M. Vasić, Geometric Inequalities, Wolters-Noordhoff, Groningen 1969.

[7] J. M. CHILD, Inequalities Connected with a Triangle, The Math. Gazette 23, No. 254 (1939), 138143.

[8] N. Dergiades, Signed distances and the Erdös-Mordell inequality, Forum Geom. 4 (2004), 67-68.

[9] P. ERdös, Problem 3740, Amer. Math. Monthly 42 (1935), 396.

[10] W. Janous, Further Inequalities of Erdös-Mordell Type, Forum Geom. 4 (2004), 203-206.

[11] D. K. KAZARINOFF, A simple proof of the Erdös-Mordell inequality for triangles, Michigan Mathematical Journal 4 (1957), 97-98.

[12] N. D. KaZarinoff, Geometric inequalities, New Math. Library, Vol. 4, Yale 1961, (pp. 78-79, 86).

[13] V. Komornik, A short proof of the Erdös-Mordell theorem, Amer. Math. Monthly 104 (1997), 57-60.

[14] H. LEE, Another Proof of the Erdös-Mordell theorem, Forum Geometricorum 1 (2001), 7-8.

[15] J. LiU, A Weighted Erdös-Mordell Inequation and Its Application, Journ. f Luoyang Norm. Univ. 5 (2002), doi: CNKI:SUN:LSZB.0.2002-05-005

[16] J. LiU, ZH.-H. ZHANG, An Erdös-Mordell Type Inequality on the Triangle, RGMIA 7 (1), 2004.

[17] J. LIU, A new proof of the Erdös-Mordell inequality, International Electronic Journal of Geometry 4, 2 (2011), 114-119.

[18] J. LIU, Some new inequalities for an interior point of a triangle, Journal of Mathematical Inequalities, Volume 6, Number 2 (2012), 195-204.

[19] Z. Lu, Erdös-Mordell type inequalities, Elemente der Mathematik 63, 1 (2008), $23-24$.

[20] B. MALEŠEviĆ, Erdös theorem in the plane of the triangle, Proceedinngs of XI and XII Meeting of Mathematical Faculty Students of Yugoslavia 1985, 245-250. (see also [21] (1988), pp. 318-320.)

[21] D. S. Mitrinović, J. E. PeČarić, V. Volenec, Recent Advances in Geometric Inequalities, Kluwer Academic Publishers, Dordrecht-Boston-London 1988.

[22] L. J. Mordell, Solution of Problem 3740, Amer. Math. Monthly 44, 4 (1937), 252-254. 
[23] A. Oppenheim, Some inequalities for a spherical triangle and an internal point, Pub. Elektrotehn. Fak. Ser. Mat. et Phys., Univ. of Belgrade, No. 203 (1967), 13-16.

[24] V. PAmbuccian, The Erdös-Mordell inequality is equivalent to non-positive curvature, Journal of Geometry 88, (2008), 134-139.

[25] R. A. Satnoianu, Erdös-Mordell Type Inequalities in a Triangle, Amer. Math. Monthly 110, 8 (2003), 727-729.

[26] G. R. Veld Kamp, The Erdös-Mordell Inequality, Nieuw Tijdschr.Wisk 45 (1957/58), 193-196.

[27] J. WARENDORFF: Erdös-Mordell inequality, WOLFRAM Demonstraction Project 2012. http://demonstrations. wolfram.com/TheErdoesMordellInequality/

[28] Y.-D. WU, A New Proff of a Weighted Erdös-Mordell Type Inequalities, Forum Geom. 8 (2008), 163 166.

[29] Y.-D. WU, C.-L. Yu, Z.-H. ZHANG, A Geometric Inequality of the Generalized Erdös-Mordell Type, J. Inequal. Pure and Appl. Math. 10, 4 (2009).

[30] Y.-D. Wu, L. Zhou, Some New Weighted Erdös-Mordell Type Inequalities, Int. J. Open Problems Compt. Math. 4, 2 (June 2011). 